UNIVERSIDADE DE SÃO PAULO

FACULDADE DE FILOSOFIA, LETRAS E CIÊNCIAS HUMANAS

DEPARTAMENTO DE FILOSOFIA

Luis Femando Oga

\title{
A TEORIA DA CIÊNCIA NO MODEIO BLACK-SCHOLES DE APREÇAMENTO DE OPÇÕES
}


LUIS FERNANDO OGA

\section{A TEORIA DA CIÊNCIA NO MODEIO BLACK-SCHOLES DE APREÇAMENTIO DE OPÇÕES}

Dissertação apresentada para obtenção do grau de Mestre em Filosofía pela Faculdade de Filosofia, Letras e Ciências Humanas da Universidade de São Paulo, sob onientação do Prof. Osvaldo Pessoa J r. 
DEDICATÓRIA

Às minhas filhas, Dora e Luisa. 


\section{RESUMO}

Oga, L. F. (2007) - A teoria da ciência no modelo Black-Scholes de apreçamento de opções, dissertação de mestrado na FFLCHUSP.

O presente trabalho pretende introduzir uma visão das Finanças sob o aspecto da Filosofia da Ciência.

Para permitir um estudo mais detalhado, optou-se por utilizar um dos modelos mais utilizados em Finanças, o modelo Black-Scholes de apreçamento de opções, e situá-lo dentro do campo de aplicação da Filosofia da Ciência.

Primeiramente buscou-se, antes de entrar numa análise do texto original que apresentou o modelo, contextualizá-lo no campo da Economia e das Finanças e reconstruir historicamente suas bases conceituais.

Em seguida são apresentados alguns dos elementos principais que caracterizam os modelos filosóficos de mudança científica posteriores à posição definida pelo positivismo lógico. Especial atenção é dada às concepções Realista e Anti-Realista da Ciência.

Ao final, é feita uma descrição de algumas peculiaridades empíricas do modelo Black-Scholes e é analisada a função do modelo dentro do campo da Economia e das Finanças.

\section{PALAVRAS-CHAVE}

Economia, finanças, filosofia da ciência, modelo Black-Scholes, opções. 


\begin{abstract}
Oga, L. F. (2007) - The theory of science in the Black-Scholes option valuation model, dissertação de mestrado na FFLCH-USP.
\end{abstract}

This work is an introduction of a Philosophy of Science view of the Finance.

We choose the Black-Scholes option valuation model, one of the most famous models of finance, and we submet it of an analysis in the Philosophy of Science point of view.

At first, we present an historical reconstruction of Black-Scholes model conceptual basis, using the original text of 1973 .

After this, we show some aspects of philosophical models of scientific change after the position defined by Positivism. Special attention is given to Realism and Anti-Realismo conception of science.

At the end, we describe some empirical aspects of Black-Scholes model and its correlation inside the Economy and Modern Theory of Finance.

\title{
KEY-WORDS
}

Economy, finance, philosophy of science, Black-Scholes model, options. 


\section{ÍNDICE}

\section{Prefácio}

1. O modelo Black-Scholes de apreçamento de opções

1.1. Economia

1.2. Finanças

1.3. Instrumentos derivativos e opções

1.4. O modelo Black-Scholes de apreçamento de opções

2. Elementos de filosofia da ciência e de filosofia da economia

2.1. As teorias da ciência

2.2. O realismo e o anti-realismo

2.3. Teorias e modelos

2.4. O instrumentalismo de Friedman

3. Considerações filosóficas acerca do modelo Black-Scholes

3.1. A estrutura lógica

3.2. A verificação empírica

3.3. Os aprimoramentos

3.4. A volatilidade

4. Conclusão

Referências bibliográficas 


\section{Prefácio}

O presente trabalho pretende introduzir uma visão das Finanças sob o aspecto da Filosofia da Ciência.

Para permitir um estudo mais detalhado, optou-se por utilizar um dos modelos mais utilizados em Finanças, o modelo Black-Scholes de apreçamento de opções, e situá-lo dentro do campo de aplicação da Filosofia da Ciência.

Primeiramente buscou-se, antes de entrar numa análise do texto original que apresentou o modelo, contextualizá-lo no campo da Economia e das Finanças e reconstruir historicamente suas bases conceituais.

Em seguida são apresentados alguns dos elementos principais que caracterizam os modelos filosóficos de mudança científica posteriores à posição definida pelo positivismo lógico. Especial atenção é dada às concepções Realista e Anti-Realista da Ciência.

Ao final, é feita uma descrição de algumas peculiaridades empíricas do modelo Black-Scholes e é analisada a função do modelo dentro do campo da Economia e das Finanças. 


\section{O modelo Black-Scholes de apreçamento de opções}

\subsection{Economia}

A Economia é o estudo da atividade de produção de bens (tudo aquilo que tem utilidade, é escasso e requer uma ação humana para sua confecção). Sua principal preocupação reside nos aspectos mensuráveis relativos a essa atividade e, para isso, recorre às ferramentas matemáticas e estatísticas. Dentre os problemas que ela enfrenta estão a otimização dos limitados recursos materiais disponíveis (matéria-prima para a produção de bens), de um lado, e a oferta, demanda e preços (valores) destes mesmos bens, de outro.

O estudo da Economia envolve várias escolas e linhas metodológicas comumente conflitantes entre si. Um dos motivos geralmente apontados para isso seria o fato de que, ao contrário de outras ciências, a Economia não é desvinculada da visão de mundo do pesquisador, cujas crenças interferem, conscientemente ou não, em seu trabalho científico. Em virtude disso, a Economia não apresenta unidade nem mesmo quanto ao seu objeto, pois este depende da visão que o economista tem do processo produtivo.

Convém notar que os economistas já foram designados como "filósofos profanos" pois "buscavam encerrar em um esquema de filosofia a mais profana das atividades humanas - a luta pela riqueza" (Heilbroner, 1996, p. 18).

Historicamente, foi a partir do século XVIII que a Economia passou a definir sua área de ação e a se diferenciar das outras ciências sociais. Duas abordagens distintas foram utilizadas para interpretar a essência da atividade econômica e para fundamentar as teses centrais dessa nova disciplina, a 
mecanicista e a organicista, sendo que posteriormente ela seria colocada no núcleo das humanidades.

Os estudiosos do grupo organicista tratavam o comportamento da Economia como se ele decorresse de um organismo vivo. A terminologia utilizada era retirada dos estudos biológicos e com ela procuravam descrever os problemas econômicos. É um exemplo dessa concepção o trecho:

[...] as partes principais da economia social são constituídas de tudo o que se refere aos organismos dos quais a sociedade se serve para a criação, distribuição e consumo dos bens, do mesmo modo que as partes principais da fisiologia do ser humano são os órgãos relativos a todas as funções inerentes ao desenvolvimento do corpo humano. (Say, [1803] 1983).

Os mecanicistas recorriam à analogia com as leis físicas para tratar das leis econômicas. Um exemplo disso pode ser constatado no seguinte texto:

Onde quer que os objetos tratados sejam passíveis de ser maior ou menor, aí as leis e relações devem ser matemáticas por natureza. O prazer e o sofrimento são - indiscutivelmente - o objeto último do cálculo da Economia. Satisfazer ao máximo às nossas necessidades com o mínimo de esforço obter o máximo do desejável à custa do mínimo indesejável — ou, em outras palavras, maximizar o prazer, é o problema da Economia. (Jevons, [1871] 1983, p. 47).

Essas duas visões, a organicista e a mecanicista, gradualmente deram espaço para a percepção de que a Economia é, de fato, uma ciência social. Ao tratar de ações humanas, não pode o estudo econômico desvincular-se dos aspectos psicológicos do processo de decisão. Nesse sentido, Lionel Robbins propôs a seguinte definição de Economia: "A Economia é uma ciência que estuda o comportamento humano como uma relação entre fins e meios escassos, os quais têm usos alternativos." (Robbins, 1935, pp. 16-7). 
A escassez é o aspecto essencial do objeto da Economia. A limitada quantidade de recursos disponíveis leva à limitada quantidade de bens. E a existência dos bens deve-se às demandas para adquiri-los. Um bem é procurado porque é útil, por sua capacidade de saciar necessidades humanas. Mas não é a validade dessas necessidades que importa à Economia, e sim a sua mera existência e o fato de poderem ser supridas pelos bens econômicos.

Desde 1969 o Banco da Suécia concede anualmente o Prêmio Nobel de Economia para aqueles cujos trabalhos foram considerados de extrema relevância nessa área do conhecimento.

\subsection{Finanças}

As Finanças correspondem à área da Economia que estuda as atividades relacionadas à gestão dos bens, ou a forma como os agentes econômicos administram seus bens ao longo do tempo. O termo "finanças" pode remeter a representações simbólicas de atividades econômicas reais.

A teoria financeira "consiste em um conjunto de conceitos que ajudam a organizar o pensamento das pessoas sobre como alocar bens ao longo do tempo e um conjunto de modelos quantitativos para ajudar as pessoas a avaliarem alternativas, tomarem decisões e implementá-las" (Bodie \& Merton, 2002, p. 32).

Até a década de 50, as Finanças não consistiam em um estudo sistemático e organizado e baseavam-se na experiência e no senso comum de seus praticantes. 
Somente após os anos 50 houve um ramo da Economia que se especializou e tornou-se praticamente independente, muitas vezes conhecido pela designação Teoria Moderna de Finanças, ao mesmo tempo em que houve uma evolução tecnológica dos mecanismos de negociação em mercado (local, teórico ou não, de encontro regular entre compradores e vendedores).

Os chamados mercados financeiros servem a uma finalidade-chave na economia, ao possibilitar a alocação de recursos entre várias áreas de produção. É através dos mercados financeiros que os recursos acumulados (poupança) são transformados em investimentos das empresas. O comportamento destes mercados reflete também as perspectivas futuras e os riscos das empresas, o que possibilita aos investidores diversificar seus riscos e adquirir valiosas informações para suas decisões de investimento.

Em 1990 três importantes trabalhos, considerados como embriões dos estudos em Finanças, deram aos seus autores o Prêmio Nobel de Economia: Harry Markowitz, Merton Miller e William Sharpe.

A seguir serão feitas breves descrições destes trabalhos, cuja leitura pode ser desconsiderada por não-iniciados no estudo das Finanças, sem prejuízo do entendimento da dissertação.

A contribuição de Harry Markowitz foi publicada primeiramente em um trabalho denominado "Portfolio Selection" (Markowitz, 1952) e, mais tarde, numa abordagem mais genérica, em seu livro Portfolio Selection: Efficient Diversification of Investment (Markowitz, 1959). A denominada teoria de seleção de carteiras desenvolvida nestes trabalhos era originalmente um agrupamento de práticas para investidores otimizarem sua alocação de 
recursos com base no retorno esperado e no risco que poderiam correr. De forma geral, naturalmente, investidores e economistas têm consciência da necessidade de fazer uma rigorosa análise de risco-retorno, conforme a máxima: "não se deve colocar todos os ovos numa mesma cesta". Markowitz formulou um procedimento operacional para seleção de carteiras que se tornou o fundamento de muitas pesquisas posteriores. Basicamente, ele mostrou que, sob determinadas circunstâncias, a escolha da carteira por um investidor pode ser feita a partir de apenas duas informações: o retorno previsto e a expectativa de variação de preços dos ativos que a compõem. Ativos financeiros são direitos decorrentes de obrigações assumidas por agentes econômicos. O risco da carteira, medida pela variação de preços, pode ser reduzido com a diversificação utilizando-se os valores estatísticos das correlações que os preços dos ativos têm entre si.

Desta forma, o complexo problema de escolha da carteira a partir de um grande gama de ativos disponíveis, cada qual com suas propriedades peculiares, é reduzido a um problema com apenas duas variáveis. O grande sucesso do modelo pode ser explicado pela sua simplicidade e adequação para aplicações empíricas. Nas palavras de Bernstein (1997, pp. 255-7):

Ao substituir a pura intuição por um cálculo estatístico da incerteza, Markowitz transformou a escolha tradicional de ações em um procedimento de seleção do que ele denominou carteiras 'eficientes'. Eficiência, um termo adotado da engenharia pelos economistas e estatísticos, significa maximizar a saída em relação à entrada ou minimizar a entrada em relação à saída. As carteiras eficientes minimizam aquela 'coisa indesejável' chamada variância ao mesmo tempo em que maximizam aquela 'coisa desejável' chamada enriquecer.

[...] 'Portfolio Selection' revolucionou a atividade de gerência de investimentos, ao elevar o risco à mesma importância do retorno esperado. O 
artigo, junto com o livro de mesmo nome que Markowitz escreveu em 1959, foi a base de quase todos os trabalhos teóricos de finanças que se seguiram.

Em termos gerais, o trabalho de Markowitz elevou a área denominada "micro-análise financeira" a um patamar respeitável dentro da pesquisa econômica.

Com o chamando Modelo de Apreçamento de Ativos de Capital, ou CAPM, que partiu dos resultados obtidos por Markowitz, mais um passo foi dado a partir da micro-análise financeira em direção à análise da formação de preços de ativos financeiros. Nos anos 60 , diversos pesquisadores - de forma independente - contribuíram para este desenvolvimento. A realização de William Sharpe neste campo surgiu em seu trabalho "Capital Asset Prices: A theory of market equilibrium under conditions of risk" (Sharpe, 1964).

O CAPM baseia-se no fato de que um investidor individual pode escolher a exposição ao risco através de uma combinação de ativos e passivos. A composição ótima desta carteira, conforme Markowitz, dependeria apenas da avaliação quanto às expectativas futuras dos preços, e não de atitudes próprias dos investidores perante o risco. A pergunta fundamental que esse modelo procura responder é: quais seriam as recompensas aos investidores por assumirem riscos (prêmios de risco) num mercado em equilíbrio, no qual os agentes têm o mesmo conjunto de previsões de retorno e de riscos e se todos escolhessem suas carteiras de acordo com o trabalho de Markowitz?

O CAPM é considerado a espinha dorsal da teoria moderna do preço para mercados financeiros. É usado também extensamente na análise empírica, de modo que a abundância de dados estatísticos financeiros possa 
ser utilizada sistematicamente e eficientemente. Além disso, o modelo é uma base importante para a tomada de decisão em áreas diferentes. Isto está relacionado ao fato que tais estudos requerem a informação sobre custos das empresas, nos quais o prêmio de risco é um componente essencial.

Enquanto os modelos de escolha de carteiras e o CAPM focalizam-se no investidor, Merton Miller — inicialmente em colaboração com Franco Modigliani — estabeleceu um método para explicar a relação, através do mercado, entre a estrutura de ativos e a política de dividendos das firmas, de um lado, e o valor de mercado e o custos de capital, de outro.

Essa explicação é baseada na suposição de que todos os agentes têm o mesmo acesso ao mercado como principal ferramenta. Isto implica que dentro dos limites de suas carteiras, os investidores podem encontrar seu próprio balanceamento entre retorno e risco. Em conseqüência, as empresas não têm que ajustar suas decisões às preferências de risco dos diversos investidores. Os administradores podem melhor proteger os interesses dos acionistas simplesmente otimizando a riqueza líquida da firma. Ou seja, não é em virtude do interesse dos investidores que as empresas reduzem seus riscos, mas apenas pelas escolhas definidas pelos acionistas.

O modelo básico foi formulado em um ensaio de Miller e Modigliani entitulado "The Cost of Capital, Corporation Finance and the Theory of Investment" (Miller \& Modigliani, 1958) seguido por outros dois estudos (Miller \& Modigliani, 1963; Miller \& Modigliani, 1966). Usando este modelo, eles derivaram os chamados Teoremas de Invariância. 
Esses teoremas afirmam que (i) o balanceamento entre ativos $e$ passivos das empresas não afeta os valores de mercado nem os custos médios de capital, e (ii) a política de dividendos de uma empresa não afeta seu valor de mercado.

Essas proposições, e seus desdobramentos "se baseiam na simples observação de que se os acionistas pudessem assumir as mesmas transações financeiras realizadas pelas empresas, nas mesmas condições e preços, poderiam reverter os efeitos de qualquer política financeira corporativa a custo zero" (Sandroni, 2005, 828).

\subsection{Instrumentos derivativos e opções}

Dentre os bens disponíveis para negociação estão os denominados "ativos financeiros": direitos decorrentes de obrigações assumidas por agentes econômicos.

Um exemplo de ativo financeiro é a "ação" de uma empresa: documento que indica ser seu possuidor o proprietário de certa fração de determinada empresa.

Os derivativos compreendem documentos cujo valor de negociação deriva (daí o nome 'derivativos') de outros ativos, denominados ativos-objeto.

Com propriedade, explica Bernstein (1997, pp. 306-7):

Por mais sofisticados que pareçam na roupagem extravagante em que os vemos atualmente, seu papel na administração do risco surgiu provavelmente há vários séculos no campo. As particularidades podem ter mudado através do tempo, mas a necessidade fundamental do agricultor de controlar o risco não mudou. Os agricultores não toleram a variação de preços, pois vivem endividados. Seus enormes investimentos em terras, equipamentos e estoques de sementes e fertilizantes tornam inviável o financiamento bancário. Antes de 
ganhar qualquer dinheiro, o agricultor deve pagar por seus insumos, plantar sua cultura e, depois, no constante temor de enchentes, seca e granizo, esperar meses até a época da colheita. Sua grande incerteza é qual será o preço quando, enfim, estiver em condições de entregar a colheita ao mercado. Se o preço que receber for inferior ao custo de produção, ele poderá não conseguir pagar as dívidas e perder tudo.

O agricultor é impotente diante dos riscos do clima e dos insetos, mas pode ao menos escapar da incerteza quanto ao preço de venda. Para isso, ele vende a colheita ao plantá-la, prometendo ao comprador a entrega futura a um preço prefixado. Seu lucro poderá ser menor se os preços subirem, mas o contrato a termo o protegerá da catástrofe se os preços caírem. Ele passou adiante para outra pessoa o risco de preços menores.

Essa outra pessoa costuma ser um processador de alimentos que enfrenta o risco oposto: ele ganhará se os preços de seus insumos caírem enquanto a cultura ainda estiver plantada, mas estará em apuros se os preços subirem e aumentarem o custo de suas matérias-primas. Ao fechar o contrato com o agricultor, o processador deixa que este assuma o risco de elevação dos preços agrícolas. Essa transação, envolvendo supostamente contratos arriscados para ambas as partes, na verdade diminui o risco total na economia.

Às vezes, o outro lado do acordo é um especulador - alguém disposto a livrar os outros da incerteza por uma convicção sobre como as coisas se desenrolarão.

[...] No século XII, os vendedores nas feiras medievais assinavam contratos, denominados lettres de faire, prometendo a entrega futura dos itens vendidos. No século XVII, os senhores feudais japoneses vendiam seu arroz para entrega futura em um mercado chamado cho-ai-mai sob contratos que os protegiam do mau tempo ou da guerra. Durante muitos anos, em mercados como de metais, de câmbio, de produtos agrícolas e, mais recentemente, de ações e títulos, os contratos para entrega futura têm sido um meio de proteção comum contra os riscos de preços voláteis. Contratos a termo para produtos primários como trigo, carne de suíno e cobre têm sido fechados no Chicago Board of Trade desde 1865 .

Desde o último quarto do século $X X$ o mercado de derivativos tem se tornado extremamente importante no mundo. Atualmente, diversos instrumentos derivativos são negociados diariamente nas mais diversas bolsas (mercados financeiros organizados destinados à negociação de ações). Por 
possibilitarem modificações em níveis de risco assumidos pelos investidores, passaram a ser largamente utilizados em estratégias de investimentos. Para chegar a esse estágio atual foi fundamental a contribuição do modelo desenvolvido por Black, Scholes e Merton no início dos anos 70.

Uma opção é um tipo de derivativo, e é um contrato que dá a seu titular o direito de comprar ou vender um ativo, sob certas condições, num determinado período de tempo (cf. Black \& Scholes, 1973, p. 637).

Mais especificamente, uma opção dá, mediante o pagamento de um prêmio, o direito de comprar ou vender um ativo a um determinado preço até uma certa data futura ${ }^{1}$.

Há registros históricos de negociação de opções na chamada "febre das tulipas" na Holanda no século XVII. Ao invés de comercializarem as próprias tulipas, os revendedores compravam opções de compra para garantir seus estoques mesmo na alta de preços. Ao revés, os plantadores compravam opções de venda para se protegerem contra eventuais quedas de preços. Nos Estados Unidos, corretores transacionavam com opções de venda e de compra de ações na década de 1790, pouco depois de o Acordo de Button Wood Tree estabelecer o que se tornaria a Bolsa de Valores de Nova York. Nesse país, o mercado "organizado" de opções surgiria somente em 1973, com o início das atividades do Chicago Board Options Exchange.

\footnotetext{
${ }^{1}$ Suponha que você queira comprar uma bicicleta de um determinado modelo e marca. Ao visitar a primeira loja, você a encontra à venda por R\$ 500,00. Parece um bom preço, você pensa, mas decide continuar pesquisando em outras lojas. Entretanto, para não correr o risco de perder um bom negócio, você entra em acordo com o vendedor: você paga R\$ 5,00 para que ele guarde a bicicleta para você até o final do dia de amanhã.
} 
Uma opção se caracteriza pelos seguintes elementos: o prêmio, ou valor da opção (valor pago para se ter o direito de comprar ou vender), o preço de exercício, ou strike (valor pelo qual o titular da opção poderá comprar ou vender o ativo), e o exercício (data limite para que o titular da opção exerça seu direito $\left.^{2}\right)$.

Um dos problemas clássicos em Finanças trata da determinação do valor do prêmio de uma opção. No final da década de 60 , a colaboração de três pesquisadores resultou no chamado Modelo Black-Scholes, publicado na edição de maio-junho de 1973 do Journal of Political Economy (Black \& Scholes, 1973). Esse trabalho deu a um de seus autores, Myron Scholes (o outro autor, Fischer Black, falecera em 1996), e a um de seus colaboradores, Robert Merton, o Prêmio Nobel de Economia de 1997.

O funcionamento dos mercados exige que os diversos agentes possam selecionar o nível apropriado de risco para suas transações. Isto ocorre nos mercados financeiros, nos quais os riscos são distribuídos entre aqueles que querem evitá-los e os que podem assumi-los. Os mercados de opções e outros derivativos são importantes no sentido que os agentes que antecipam os rendimentos ou pagamentos futuros podem assegurar um determinado lucro ou se precaver de uma perda acima de um determinado nível. Um pré-requisito para que essa distribuição seja eficiente, entretanto, é que tais instrumentos opções e demais derivativos - estejam apreçados corretamente. E um método para determinar o valor desses derivativos teve forte influência nas ciências econômicas nas últimas três décadas do século XX.

\footnotetext{
${ }^{2}$ No exemplo utilizado na nota anterior, o ativo é a bicicleta, o prêmio é $\mathrm{R} \$ 5,00$, o strike é $\mathrm{R} \$ 500,00$ e o exercício é o final do dia de amanhã.
} 


\subsection{O Modelo Black-Scholes de apreçamento de opções}

Robert Merton, Myron Scholes e Fischer Black desenvolveram, em colaboração, uma solução para o problema do apreçamento de uma opção. Em 1973, Black e Scholes publicaram o que veio a ser difundido mundialmente como a fórmula Black-Scholes. Atualmente, um sem-número de negociantes e investidores usam esta fórmula para avaliar as opções disponíveis no mercado.

Este método tem uma ampla gama de aplicabilidade e criou novas áreas de pesquisa, inclusive fora da economia financeira. Métodos derivados podem ser usados para avaliar contratos e garantias de seguro, ou a viabilidade de vários tipos de projeto.

A proposta de Black-Scholes é determinar o preço de uma opção de compra somente em função do preço do ativo e de outras variáveis conhecidas. Para isso, são estabelecidas as seguintes hipóteses:

a) a taxa de juros livre de risco é constante ao longo do tempo;

b) o preço do ativo segue um caminho aleatório (denominado "random walk"), com distribuição lognormal e volatilidade (característica associada à variação de valores) constante dos retornos diários;

c) o ativo não paga dividendos ou outros benefícios;

d) a opção é do tipo européia, isto é, somente pode ser exercida na data limite de exercício;

e) não há custos de transação na compra ou venda do ativo ou da opção;

f) é possível negociar qualquer quantidade fracionária do ativo; 
g) é possível ficar em posição "vendida" em opções, ou seja, é possível realizar operação de venda sem ter o derivativo.

Estabelecidas essas condições, é preciso examinar um tipo de operação conhecida como delta hedge.

Hedge pode ser entendido como uma operação de proteção no mercado financeiro. Isso traz dois importantes significados: é uma operação não especulativa, ou seja, não visa ao lucro proporcionado pelas oscilações das variáveis de mercado (ao contrário, visa à proteção a essas oscilações) e é uma operação que diminui significativamente o risco de uma carteira.

Assim, utilizando a notação de Black-Scholes, definindo $w(x, t)$ para o valor do prêmio da opção como uma função do preço do ativo $(x)$ e do tempo $(t)$, o número de opções que devem ser vendidas para proteger uma posição unitária comprada do ativo é:

$$
1 / w_{1}(x, t)
$$

na qual o índice "1" indica a derivada parcial de $w(x, t)$ em relação ao seu primeiro argumento ${ }^{3}$.

Para compreender o significado de (1) é preciso analisar o comportamento que prêmios e ativos guardam entre si durante o período até o exercício.

\footnotetext{
3 "Writing $w(x, t)$ for the value of the option as a function of the stock price $x$ and time $t$, the number of options that must be sold short against one share of stock long is:

$$
1 / w_{1}(x, t)
$$

In expression (1), the subscript refers to the partial derivative of $w(x, t)$ with respect to its first argument." (Black \& Scholes, 1973, p. 641)
} 
Imagine que um ativo (por exemplo, uma ação de uma determinada empresa X) custe $\mathrm{R} \$ 100,00$ no exercício. Nessa data (exercício ou vencimento de opções), uma opção de compra da ação X cujo strike (ou preço de exercício) seja $R \$ 100,00$ teria como preço justo $R \$ 0,00$. Isso ocorre porque ninguém pagaria valor algum para ter o direito de comprar a ação $X$ por $R \$$ 100,00 nessa data uma vez que o seu preço de mercado é exatamente $R \$$ 100,00 . Analogamente, se o preço de mercado de $X$ fosse $R \$ 101,00$ o preço justo dessa opção de compra (cujo strike é $R \$ 100,00$ ) seria $R \$ 1,00$.

Entretanto, a vinte dias úteis do exercício uma opção de strike $R \$ 100,00$ não valerá $R \$ 0,00$ se o ativo estiver a exatamente $R \$ 100,00$. Seu valor muito provavelmente será maior que isso. Ela poderia valer, por exemplo, $\mathrm{R} \$ 0,50$. Esses cinqüenta centavos acima de $\mathrm{R} \$ 0,00$ devem-se a fatores como volatilidade do ativo, prazo até o exercício e taxa de juros livre de risco.

Suponha que 0 ativo passe de $R \$ 100,00$ para $R \$ 102,00$. Acompanhando essa alta, a opção poderá passar de $\mathrm{R} \$ 0,50$ para, por exemplo, $\mathrm{R} \$ 1,50$.

Ou seja, nesse exemplo, uma variação de $\mathrm{R} \$ 2,00$ no preço do ativo acarretou uma variação de $R \$ 1,00$ no prêmio (preço da opção). A relação entre essas duas sensibilidades é denominada delta da opção, e está denotada por $w_{1}(x, t)$ na equação (1). Assim, poderíamos afirmar que o valor do delta é aproximadamente 0,5 :

$$
\text { delta }=w_{1}(x, t)=\frac{\partial w}{\partial x} \approx \frac{1,00}{2,00}=0,5
$$


No exemplo em questão considere que o valor de $w_{1}(x, t)$ é 0,5 (delta da opção). Assim, para cada posição comprada em 1 quantidade da ação $X$ devese ter duas quantidades vendidas da opção para proteger a carteira. Isso significa que, para proteger uma aplicação de uma quantidades na ação X, basta vender (ficar numa posição vendida) duas quantidades da opção em análise.

Se se quiser então formar uma carteira "protegida" (hedgeada) com uma quantidade da ação, ter-se-á que vender duas quantidades da opção.

O valor dessa carteira na situação inicial $(x=R \$ 100,00$ e $w=R \$ 0,50)$ seria:

$$
100-0,5 * 2=99
$$

E pode-se constatar que numa situação final $(x=R \$ 102,00$ e $w=R \$$ 1,50) o valor da carteira será denotado por:

$$
102-1,5 * 2=99
$$

Resultado que comprova a proteção da carteira. Black-Scholes exprime esse valor genericamente:

$$
x-\frac{w}{w_{1}}
$$

Como foi demonstrado, mudanças no valor da ação, supondo constante o valor de $w_{1}$, não alteram o valor da carteira.

Considerando as alterações nas variáveis, tem-se que o valor da carteira pode ser denotado por:

$$
\Delta x-\frac{\Delta w}{w_{1}}
$$


O modelo se desenvolve a partir da adoção de resultados matemáticos acerca dos processos estocásticos.

Entende-se por processo estocástico o comportamento seguido por qualquer variável cujo valor varie aleatoriamente com o tempo, seja em tempo discreto ou tempo contínuo.

Apesar de o preço das ações mudar de forma discreta em relação ao tempo e assumir, também, valores discretos, a abordagem do cálculo estocástico em tempo contínuo é considerada adequada para seu modelamento. Implicitamente, isso significa uma outra hipótese de BlackScholes.

O denominado processo de Markov é um tipo específico de processo estocástico, no qual apenas o valor atual de uma variável é suficiente para fazer considerações acerca de seu futuro. E o modelo de Wiener corresponde à modelagem do Modelo Browniano Geométrico, conforme expõe Hull (1998, p. 230):

Os modelos de comportamento dos preços das ações são comumente expressos em termos do que é conhecido por processos de Wiener. Um processo de Wiener é um tipo específico de processo estocástico de Markov, que tem sido utilizado pela física para descrever o movimento de uma partícula sujeita a uma grande quantidade de pequenos choques, às vezes denominado de movimento browniano.

Se uma variável $x$ segue o processo generalizado de Wiener, o comportamento dela pode ser denotado por:

$$
d x=a d t+b d z
$$

Na qual:

1. a e b são constantes; 
2. t é o tempo; e

3. z é uma variável tal que $d z=\varepsilon \sqrt{\Delta t}$, onde $\varepsilon$ é uma variável aleatória de distribuição normal padronizada (média zero e desvio padrão 1).

Entretanto, se considerarmos que as variáveis a e b não são constantes mas dependentes do próprio valor de $\mathrm{x}$ e do tempo, tem-se o denominado processo de Itô:

$$
d x=a(x, t) d t+b(x, t) d z
$$

A esse processo assemelha-se o preço da ação. Preservando a notação de Black-Scholes, tem-se o modelo de comportamento dos preços das ações mais amplamente utilizado:

$$
d x=\mu x d t+\sigma x d z
$$

Nessa expressão, o parâmetro $\mu$ representa o retorno médio esperado da ação num curto período de tempo, e $\sigma$ a volatilidade futura da ação também em um curto período de tempo. Ambas as variáveis são expressas em termos porcentuais, daí a necessidade de elas estarem multiplicadas pelo preço atual da ação, $x$, na expressão (6).

Estando clara a analogia entre o processo de Itô e a modelagem mais amplamente utilizada para o comportamento de ações, expressões (5) e (6), aplica-se o lema de Itô, instituído pelo matemático K. Itô (Itô, 1951).

O lema de Itô afirma que se uma expressão $G$ é função de $x$ e $t$, ela segue o processo:

$$
d G=\left(\frac{\partial G}{\partial x} a+\frac{\partial G}{\partial t}+\frac{1}{2} \frac{\partial^{2} G}{\partial x^{2}} b^{2}\right) d t+\frac{\partial G}{\partial x} b d z
$$


Considerando G como a variável $w$, que é o preço da opção (que é função de x e t) e utilizando a versão discreta da equação (6), tem-se:

$$
\Delta w=w_{1} \Delta x+\frac{1}{2} w_{11} \sigma^{2} x^{2} \Delta t+w_{2} \Delta t
$$

Observando a notação original de Black-Scholes, $w_{11}$ representa a derivada parcial de $w_{1}$ em relação ao tempo (ver nota 3).

Retornando à expressão (3), que denota a variação no valor de uma carteira hedgeada (protegida) formada por 1 quantidade da ação e $1 / w_{1}$ quantidades da opção em análise:

$$
\Delta x-\frac{\Delta w}{w_{1}}
$$

Substituindo (8) em (3), tem-se:

$$
\Delta x-\frac{\left(w_{1} \Delta x+\frac{1}{2} w_{11} \sigma^{2} x^{2} \Delta t+w_{2} \Delta t\right)}{w_{1}}=\frac{-\left(\frac{1}{2} w_{11} \sigma^{2} x^{2}+w_{2}\right) \Delta t}{w_{1}}
$$

Cabe agora uma análise em termos de negociação. Uma vez que é possível montar a carteira hedgeada em análise, pode-se tê-la comprada ou vendida. Ou seja, no mercado de ações e opções é possível tanto comprar quanto vender quantidades, e ter como resultado uma posição comprada ou vendida. Dessa forma, o mercado iria "zerar as expectativas" ${ }^{4}$, fazendo com que a variação da carteira seja equivalente à variação de taxa de juros livre de

\footnotetext{
${ }^{4}$ Esse comportamento do mercado decorre da hipótese de que os agentes (participantes) são racionais e buscam, sempre e incessantemente, otimizar sua posição buscando o maior retorno com o menor risco.
} 
risco durante o período. Emprestando de Hull a notação П para denotar o valor da carteira, tem-se ${ }^{5}$ :

$$
\frac{\Delta \Pi}{\Pi}=r \Delta t \Rightarrow \Delta \Pi=\Pi r \Delta t
$$

Substituindo (3) e (9) em (10) tem-se:

$$
\frac{-\left(\frac{1}{2} w_{11} \sigma^{2} x^{2}+w_{2}\right) \Delta t}{w_{1}}=\left(x-\frac{w}{w_{1}}\right) r \Delta t \Rightarrow w_{2}=r w-r x w_{1}-\frac{1}{2} \sigma^{2} x^{2} w_{11}
$$

que é a Equação Diferencial de Black-Scholes.

A solução dessa equação diferencial foi referenciada no artigo de BlackScholes (1973) como uma das aplicações de uma modelagem originalmente formulada em Transferência de Calor. Em Hull, há uma dedução a partir da análise do valor esperado da opção na data de exercício e considerando a normalidade dos retornos contínuos do preço da ação. De qualquer forma, a expressão mais difundida do Modelo Black-Scholes é a solução da equação diferencial (11), dada por:

$$
w=x \cdot N\left(d_{1}\right)-S \cdot e^{-r \cdot(T-t)} \cdot N\left(d_{2}\right)
$$

na qual:

$$
\begin{gathered}
d_{1}=\frac{\ln \left(\frac{x}{S}\right)+\left(r+\frac{\sigma^{2}}{2}\right) \cdot(T-t)}{\sigma \cdot \sqrt{T-t}} \\
d_{2}=d_{1}-\sigma \cdot \sqrt{T-t}
\end{gathered}
$$

\footnotetext{
${ }^{5}$ Nos EUA a capitalização utilizada é do tipo contínua, na qual o fator de atualização de uma carteira submetida a uma taxa de juros $r$ num intervalo de tempo $\Delta$ t é:
}

$$
e^{r \Delta t}
$$


Na notação acima, S é o preço de exercício (ou strike) e ( $T$ - $t$ ) é o prazo, em dias úteis, até o vencimento. A função denotada por " $N(d)$ " é a acumulada normal padrão, ou seja, é a probabilidade de um valor ser menor que $d$.

Em suma, o modelo proposto por Black-Scholes em 1973 propõe o apreçamento de opções de compra através da equação (12). Essa equação é uma função dos parâmetros que definem o derivativo (o preço de exercício, ou strike, o prazo até o vencimento e o preço atual do ativo), da taxa de juros livre de risco vigente no mercado e da volatilidade.

O Prêmio Nobel de Economia de 1997, concedido aos criadores desse modelo, foi um reconhecimento ao impacto que o trabalho de Black-Scholes teve no estudo das Finanças. Conforme Scholes e Merton puderam apresentar em seus lectures do Nobel, seu modelo teve papel fundamental no fortalecimento da grande expansão do uso dos mercados derivativos em escala global (cf. Merton, 1997).

Na prática, a utilização do modelo pelos operadores ${ }^{6}$ adquire uma práxis peculiar, nas palavras de Hull (1998, p. 557):

[...] fica evidente que o modelo Black-Scholes proporciona uma descrição menos que perfeita do mundo real. Os preços das ações e de outros ativos exibem um comportamento mais complexo do que o movimento browniano geométrico. Por que, então, profissionais de mercado continuam a utilizá-lo?

Um motivo é a facilidade de sua aplicação. Há apenas um parâmetro que não é observável no mercado - a volatilidade. Os profissionais podem, de forma não-ambígua, deduzir volatilidades a partir dos preços das opções e preços das opções a partir das volatilidades.

[...] Outro motivo da popularidade do modelo Black-Scholes reside no fato de os profissionais terem desenvolvido o que podemos chamar de "manhas" para lidar com suas imperfeições. (Hull, 1998, p. 557).

\footnotetext{
${ }^{6}$ Pode-se considerar como “operadores” qualquer agente que diretamente faça compras ou vendas no mercado de opções.
} 


\section{Elementos de Filosofia da Ciência e de Filosofia da Economia}

\subsection{As Teorias da Ciência}

É irrefutável a posição de destaque que a Ciência encontra na cultura, tanto na sociedade quanto no ambiente acadêmico ou intelectual. Confia-se muito mais nas afirmações científicas, talvez porque elas estejam associadas à noção de progresso ou porque elas representam a própria produção do conhecimento humano, do que em explicações que venham de outras formas de manifestação do saber.

Esta condição moveu uma considerável quantidade de filósofos a exporem as mais variadas explicações para o funcionamento das ciências. A dinâmica da Ciência, examinada, contudo, não forneceu um painel geral de funcionamento, nem uma teoria única que tenha encontrado consenso.

Nesse capítulo pretende-se abordar, de uma forma muito ampla, algumas das principais correntes e teses que cercaram e ainda cercam as discussões dos filósofos da ciência, como subsídio ao tratamento de alguns aspectos do Modelo Black-Scholes que têm interesse filosófico.

Uma posição filosófica bem definida e que merece atenção inicial foi o denominado Positivismo Lógico ou Empirismo Lógico. O que compõe a visão ortodoxa da Filosofia da Ciência, contudo, foi um desdobramento ou produto do Positivismo Lógico, chamado de Visão Recebida. Cabe notar que a Visão Recebida perdurou mesmo após a superação do Positivismo Lógico “(...) pois 
se propunha a ser uma Filosofia da Ciência, e não uma epistemologia geral" (Suppe, 1977, p.6).

Conforme a Visão Recebida, as teorias científicas são compostas por axiomas, que dão origem a conceitos teóricos primitivos, definidos implicitamente, e conceitos derivados, definidos explicitamente. Esses dois tipos de conceito são então ligados, através de regras de correspondência, a conceitos empíricos, que se referem a itens da observação (diretamente observáveis). Feigl recorre ao seguinte esquema para ilustrar a estrutura lógica de uma teoria científica (cf. Feigl, [1970] 2004, p. 268):

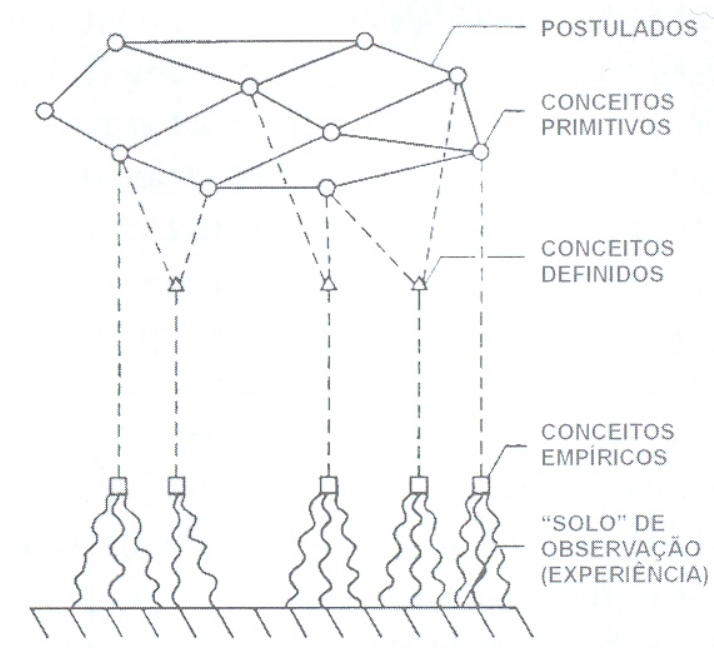

Figura 1: Esquema da estrutura lógica de uma teoria científica.

Ou seja, uma teoria científica é um sistema axiomático no qual há postulados teóricos formulados em linguagem teórica na lógica de $1^{\text {a }}$ ordem e regras de correspondência que determinam as aplicações teóricas a fenômenos empíricos e é sujeita a testes para adquirir um grau de confirmação. 
A Visão Recebida recebeu um grande número de críticas, foi defendida e se desenvolveu antes de ter sido abandonada pela maioria dos filósofos. Dentre estas críticas, podem-se citar (cf. Pessoa, 2004, pp.261-2):

I. não é clara a distinção entre conceitos teóricos e empíricos;

II. a introdução de uma nova regra de correspondência alteraria toda a teoria;

III. um grande número de teorias não seriam passíveis de reformulação axiomática;

IV. não haveria grandes vantagens na axiomatização de teorias;

V. os itens da observação estariam carregados de teoria - não haveria observações neutras na ciência;

VI. a determinação daquilo que seria "diretamente observável" tem critério vago;

VII. os testes empíricos de uma teoria isolada seriam irrelevantes, uma vez que as teorias são testadas entre si;

VIII. os conceitos teóricos podem ser compreendidos de maneira completa, sem a necessidade de correspondência com conceitos empíricos;

IX. a distinção observacional-teórico não poderia ser feita de maneira satisfatória;

X. os procedimentos de aplicação da teoria aos fenômenos observáveis não fariam parte da teoria;

XI. a utilização exclusiva da lógica clássica (por exemplo, sem admitir operadores de modalidade) seria muito restritiva; 
XII. o grau de confirmação seria uma medida probabilista; e

XIII. testes empíricos não testam apenas um único postulado, mas toda a teoria.

Como alternativas à Visão Recebida, a partir dos anos 60 novas Teorias da Ciência foram desenvolvidas através dos trabalhos de Thomas Kuhn, N.R. Hanson, Paul Feyerabend e Stephen Toulmin, dentre outros. Essas teorias deram especial ênfase a algumas crenças já subsistentes: a) a história é fonte e, pelo menos, árbitro parcial de afirmações filosóficas sobre a ciência; b) a ciência é o exemplo mais surpreendente e bem-sucedido de racionalidade em nossa cultura e c) nenhuma filosofia da ciência é digna de crédito se não enfrentar o escrutínio empírico com base na prática científica (cf. Laudan et al., 1986).

Para estes filósofos, a ciência utiliza conjuntos de paradigmas, que são mais amplos que teorias estabelecidas, com maior domínio de aplicação e com influência em vários campos científicos. Compõem-se de conceitos de longa duração e estabelecem critérios para criação de novas teorias. Podem ser vistas, também, como um conjunto de crenças, valores e técnicas compartilhadas por uma comunidade científica. Dentre exemplos de paradigmas podem-se citar: a mecânica newtoniana, a evolução darwiniana e a teoria da relatividade.

Uma sugestão de trabalho a ser realizado futuramente é a pesquisa sobre os paradigmas na Economia e nas Finanças. Nessas ciências, não há um único paradigma dominante, o que encaixaria a Economia na situação denominada por Kuhn de "ciência pré-paradigmática". Essa expressão, porém, 
parece supor que o ramo da ciência um dia será dominado por um único paradigma, o que no caso das ciências humanas é motivo de debate. Por outro lado, o que marca a ciência nesse estágio é a existência de mais de um paradigma ou, se se quiser, mini-paradigma. Assim, parece mais adequado chamar este estágio de "ciência multi-paradigmática".

Os paradigmas teriam uma grande capacidade de lidar com problemas científicos. Eles identificam e dirigem a solução de problemas, permitem a construção de modelos e evidenciam a capacidade de novas teorias em resolver problemas. Permitem que teorias possam ser modificadas para que possam se tornar mais poderosas no apontamento de solução de problemas.

O êxito em resolver problemas é uma das principais causas determinantes da aceitabilidade de paradigmas. Ao lado dessa capacidade, é também considerado o êxito em fazer novas previsões com grande precisão empírica. Entretanto, é freqüente a afirmação de que a escolha de paradigmas nunca é feita exclusivamente a partir de dados. Há diversos fatores ditos não epistêmicos, como os metafísicos, teológicos e políticos, que têm papel igualmente determinante.

Na vigência de um paradigma ocorre um consenso acerca da natureza física, sobre técnicas e procedimentos bem como o que seria aceitável como solução e como problemas a serem enfrentados. A simples existência de dificuldades empíricas não é suficiente para que a comunidade abandone um determinado paradigma. Os juízos que os cientistas fazem sobre uma ou outra teoria em particular não são absolutos, mas sempre em relação a teorias rivais, que sempre coexistem. Há quem distinga períodos onde há prevalência de 
consenso em torno de um paradigma daqueles onde vigora a competição entre paradigmas. É forçoso notar que, em qualquer caso, é freqüente a constatação de utilização de paradigmas em competição simultaneamente na pesquisa científica, especialmente em períodos de crise de um paradigma vigente, ou no estágio de ciência multi-paradigmática.

Um paradigma começa a enfraquecer quando se depara com dificuldades empíricas persistentes, deixa de prever novos fenômenos ou perde a capacidade de identificar, dar solução ou de dirigir o enfrentamento a problemas. Contudo, a rejeição de um paradigma é sempre feita com a substituição por outro paradigma disponível.

A substituição de um paradigma em crise por outro gera tanto ganhos quanto perdas. É raro que o novo paradigma comporte todos os êxitos explicativos de seu predecessor. Porém, é importante ressaltar que um novo paradigma não é julgado pela comunidade com as mesmas medidas utilizadas no exame do seu antecessor.

Assim, é bastante controverso em quais aspectos se ganha e se perde no processo de substituição de paradigmas em relação não apenas a êxitos explicativos, mas também a generalidade, precisão empírica, tratamento de problemas e capacidade preditiva.

\subsection{O Realismo e o Anti-Realismo}

Desde o início da década de 70 , acirraram-se os debates acerca do chamado realismo científico, que seria "um conjunto integrado e híbrido de 
teses filosóficas a respeito de diferentes aspectos ou dimensões da ciência" (Plastino, 1995, p. 8), que partiria de algumas teses:

1) existe um mundo exterior independente do sujeito;

2) a ciência busca apresentar teorias que representem os elementos e a estrutura do mundo; e

3) o acesso epistêmico ao mundo é possível.

Em suma, pode-se considerar que, para os realistas, "as teorias científicas possuem um valor-de-verdade (o verdadeiro ou o falso), uma vez que os enunciados teóricos referem a entidades externas à teoria, sendo que estas entidades realmente existem" (Silva, 1998, p. 7).

Para o realista em geral, o realismo de teorias implica no realismo de entidades. Ou seja, o fato de uma teoria ser verdadeira implica que as entidades inobserváveis postuladas por ela têm existência real. Essa imagem realista tradicional é por vezes renegada por outros realistas que não defendem a interpretação literal da linguagem científica e para os quais as entidades são conjuntos de resumos de certas características observáveis e não denotariam objetos específicos e determinados: o realismo de teorias não implica no realismo de entidades.

Conforme Plastino (1995, p. 9), uma visão realista da ciência pode conter as seguintes proposições:

I. A existência e a natureza dos fatos do mundo não dependem das teorias ou métodos que a ciência utiliza.

II. Toda asserção científica, interpretada literalmente, é ou verdadeira ou falsa. 
III. O valor-de-verdade de uma asserção científica é determinado pelo mundo. Uma asserção é verdadeira quando mantém uma relação de correspondência com o mundo.

IV. A ciência procura teorias que façam uma descrição verdadeira (ou aproximadamente verdadeira) do mundo.

V. Os termos teóricos preservam sua referência durante as mudanças científicas. As teorias científicas sucessoras incorporam o cerne das teorias precedentes.

VI. O progresso da ciência consiste num processo convergente de aproximação de uma teoria científica completa e verdadeira.

VII. Nas ciências maduras, as teorias são aproximadamente verdadeiras e seus termos centrais referem-se a objetos do mundo.

Dentro dessas teses, conforme os anti-realistas, haveria um conflito entre "a autonomia metafísica do mundo e sua acessibilidade epistemológica" (Horwich, 1990, p. 57).

Para os anti-realistas, como Bas van Fraassen (cf. van Fraassen, 1980), a maior qualidade de uma teoria científica está na sua adequação empírica. Uma teoria é aceita pela sua capacidade de prever fenômenos, e não porque corresponde à verdade. Para ele, ainda, as entidades inobserváveis são como personagens de ficção literária, que podem ser reais ou não.

Realistas e anti-realistas concordam que a capacidade preditiva é uma virtude epistêmica fundamental para a aceitação de teorias científicas, 
conforme resposta dada pelos empiristas lógicos para a questão da confirmação de teorias.

O realista em geral, entretanto, vai além: afirma que a aceitação de uma teoria ocorre exatamente porque ela é aproximadamente verdadeira. Essa é a posição que encontramos, por exemplo, em Richard Boyd (cf. Boyd, 1973). Ou seja, a concepção de verdade é de correspondência: se uma teoria é verdadeira, o que ela descreve corresponde à realidade. Ele quer, ou se propõe, a explicar o êxito da ciência. O sucesso de uma teoria seria uma evidência de que ela é verdadeira, caso contrário teria-se uma situação de "coincidência cósmica" ou "milagre". Além disso, há o realismo em relação às entidades inobserváveis previstas nas teorias: se a teoria é aceita, as entidades por ela postuladas existem (são reais).

Os anti-realistas apontam que, nos casos em que duas ou mais teorias possuam mesma capacidade preditiva mas que postulam entidades distintas, é impossível determinar qual delas está mais próxima da verdade. Neste caso, trata-se de teorias subdeterminadas pelas observações.

O realista se propõe a explicar o êxito da ciência. A crença numa teoria não se esgota na crença em sua capacidade preditiva, mas deve acarretar na crença de sua verdade aproximada. Para ele, as teorias têm a capacidade de realizar descobertas (porque são aproximadamente verdadeiras) e, para isso haveriam dispositivos que permitiriam ajustar os mecanismos de referência, tornando-os cada vez mais exatos.

Entretanto, o conceito de verdade aproximada pode ser um tanto vago na tentativa de conviver com o uso da metáfora, com a aceitação da verdade 
como correspondência e com a crença na literalidade das teorias e de suas entidades inobserváveis. Se uma teoria deve ser aproximadamente verdadeira porque contém certas partes verdadeiras, ainda que contenha outras que são falsas, em que medida pode-se afirmar que a teoria, como um todo, é aproximadamente verdadeira? Ou, em senso contrário, o que garantiria afirmar que uma teoria é falsa?

Para o realista é possível manter nossas idéias ordinárias sobre o que conhecemos, e não haveria dificuldade em manter as características de autonomia metafísica do mundo e sua acessibilidade epistemológica. Uma teoria, ainda que aproximadamente verdadeira, pode conter alguns grãos de falsidade. À medida que esses grãos não afetem a capacidade preditiva da teoria, ela pode continuar sendo aceita. Contudo, a confirmação de uma teoria poderá ser abalada no momento em que sua capacidade preditiva, ou de realizar descobertas, falhar. A substituição dessa teoria por outra, mais próxima da verdade, conduzirá a um refinamento sobre o entendimento do mundo.

\subsection{Teorias e modelos}

A Visão Recebida coloca a teoria, entendida como uma entidade lingüística, no centro de suas investigações acerca do funcionamento da ciência. De maneira mais abrangente, para os filósofos da ciência posteriores, falar em paradigma seria tratar de conjuntos de teorias e das implicações daí decorrentes - crenças, valores e técnicas compartilhadas por uma comunidade científica, incluindo-se conhecimentos tácitos, não expressáveis de maneira lingüística. 
A referência aos modelos, afirma grande parte dos filósofos da ciência, é crucial para o entendimento das teorias científicas. Há correntes que sustentam que as teorias devem ser consideradas como famílias de modelos. Elas constituem a "visão semântica de teorias", que se opõem à visão "sintética" da visão recebida. Mas é preciso primeiro clarificar as duas principais formas pelas quais o termo "modelo" é empregado pelos filósofos da ciência.

A primeira refere-se a modelos como estruturas matemáticas, que permitem interpretar a linguagem utilizada na axiomatização de teorias. Nesse sentido, um modelo é qualquer coisa que satisfaça os axiomas da teoria, é qualquer sistema ao qual a teoria pode ser aplicada e seus teoremas serem verdadeiros. Em geral, na lógica, tais modelos são predicados conjuntistas (formulados em uma teoria de conjuntos) que são interpretados (ou seja, atribuem-se valores de verdade a predicados envolvendo elementos dos conjuntos) de maneira a satisfazer os axiomas e teoremas da teoria lógica. A abordagem semântica das teorias científicas trata os postulados como formulações lingüísticas que não podem ser interpretadas literalmente. O conjunto de postulados não define a teoria, mas remete a ela. Conforme explica Suppe (1989, p. 82):

Tal como realmente empregadas pelos cientistas profissionais, as teorias admitem algumas formulações lingüísticas alternativas - por exemplo, a mecânica clássica de partículas recebe às vezes uma formulação lagrangeana, outras vezes, uma formulação hamiltoniana - mas é a mesma teoria, independentemente da formulação que é empregada. Como tal, as teorias científicas não podem ser identificadas com suas formulações lingüísticas; ao contrário, elas são entidades extralingüísticas às quais nos referimos e que são descritas pelas diversas formulações lingüísticas. Isso sugere que as teorias são interpretadas como estruturas abstratas propostas, que servem de modelos para conjuntos de sentenças interpretadas, que constituem as formulações 
lingüísticas. Estas estruturas são modelos metamatemáticos de suas formulações lingüísticas, sendo que a mesma estrutura pode ser modelo de diferentes, e possivelmente não-equivalentes, conjuntos de sentenças e formulações lingüísticas da teoria.

A outra forma de se conceberem os modelos é considerá-los como versões simplificadas de uma teoria, ou como representações físicas. Suppe refere-se a esse tipo de modelo como "um modelo em escala, um modelo de avião, um modelo de túnel de vento etc. É fundamental para essa noção a idéia de que um modelo é um modelo de alguma coisa ou tipo de coisa, e que funciona como um ícone daquilo que modela — isto é, o modelo é estruturalmente similar (isomórfico) àquilo que ele modela. Vou me referir a eles como modelos icônicos" (Suppe, 1977, pp. 96-7).

Para alguns autores, com relação a esta segunda acepção de modelo, é feita uma distinção entre a concepção icônica — física - e a abstrata, verbal ou simbólica de coisas ou tipos de coisas.

Outra forma de se conceber os modelos, ainda nesta segunda acepção, é a que é fornecida por Giere (cf. 1999, pp. 165-9). Para ele, um “modelo" seria um sistema idealizado e abstrato caracterizado por um conjunto definido de equações que guardaria similaridade ao sistema real na medida dada pelas "hipóteses teóricas" assumidas. Uma teoria abrangeria um conjunto de modelos e as hipóteses por eles compartilhadas e sua estrutura pode ou não ser semelhante a processos reais. Para ele é apreciável que cientistas tendam a fazer referência a ajustes entre os modelos e o mundo real. 
O Black-Scholes pode ser visto como um modelo, na acepção de Giere, devido à sua caracterização por uma equação, limitada às hipóteses assumidas, e ao auto-fomento de pesquisas sobre "ajustes" a ele próprio.

Enquanto teoria, se o Black-Scholes for considerado em conjunto com outras teorias, que implicaram numa séria de crenças, valores e técnicas compartilhadas por uma comunidade.

E como paradigma, uma vez que as hipóteses do Black-Scholes encerram conhecimentos tácitos, não expressos de maneira lingüística (p. ex.: Princípio da não-arbitragem).

Para o presente texto, é preferível continuar a tratá-lo como modelo, ficando uma análise "expansionista" como sugestão de trabalhos futuros.

O Modelo Black-Scholes de apreçamento de opções permitiu a rápida expansão da chamada "indústria acadêmica de pesquisas em derivativos" ${ }^{7}$, à medida que sua formulação inspirou modelos de apreçamento de uma vasta gama de outros produtos financeiros e o desenvolvimento de várias características desses produtos, permitindo uma maior sofisticação na troca de risco entre investidores no mercado. No capítulo 3 será feita uma análise dos pressupostos e características do Modelo Black-Scholes que foram responsáveis pelo seu sucesso e, por outro lado, pelas principais críticas e estudos que se seguiram visando atenuar suas limitações.

\subsection{O Instrumentalismo de Friedman}

\footnotetext{
${ }^{7}$ A expressão usada por Scholes (1997, p. 127) foi “academic industry in derivative research”.
} 
No campo da Metodologia da Economia, especialmente na segunda metade do século $\mathrm{XX}$, ganhou destaque o ensaio de Milton Friedman (Friedman, 1953), na qual é exposta uma visão instrumentalista para a abordagem das teorias e das hipóteses em economia.

As idéias de Friedman, centradas na tese de que os economistas não deveriam se importar com o "realismo" das hipóteses de suas teorias, geraram grande controvérsia e muitos debates metodológicos entre os economistas.

Friedman inicia seu ensaio contrapondo as noções de ciência normativa e ciência positiva. Para ele, a ciência dita normativa tem a capacidade apenas de apontar aquilo que seria desejável para os sujeitos, sem qualquer caráter científico. A ciência propriamente, objetiva, seria aquela isenta da visão de mundo do sujeito cognoscente, axiologicamente neutra, à qual a Economia deveria se ajustar ou se comportar:

A tarefa dessa economia positiva é a de provar um sistema de generalizações passível de ser utilizado para fazer previsões corretas acerca das conseqüências de qualquer alteração das circunstâncias. $O$ desempenho de uma tal economia será ajuizado em termos da precisão e do alcance das previsões e em termos do ajuste que haja entre tais previsões e a experiência. (Friedman, 1981, p. 164).

A realidade produziria regularidades que seriam capturadas pelas teorias científicas. E o objetivo das teorias científicas seria realizar previsões:

Considerada um corpo de hipóteses substantivas, a teoria deve ser julgada por meio de seu poder previsivo com relação à classe de fenômenos que pretende 'explicar'. Somente a prova factual poderá demonstrar se ela é 'certa' ou 'errada' ou, melhor dizendo, 'aceita' como válida ou 'rejeitada'. (Friedman, 1953, p. 8). 
Nesse ponto pode-se identificar o posicionamento de Friedman enquanto instrumentalista e anti-realista em relação às teorias científicas. Contudo, ele prossegue em seu artigo afirmando que os testes de validade das previsões de uma teoria difere dos de suas hipóteses, pois o "número de fatos observados é invariavelmente infinito ao passo que o número de hipóteses possíveis é infinito" (Friedman, 1981, pp. 169-70).

Friedman propõe que a escolha de hipóteses deve ser feita com base na simplicidade e na capacidade explicativa:

Uma hipótese é importante quando 'explica' muito com base em pouco, ou seja, quando está em condições de delimitar, por abstração, partindo da massa de circunstâncias complexas e pormenorizadas que cercam o fenômeno a explicar, uma classe de elementos comuns e fundamentais, formulando previsões válidas cujo alicerce é, justamente, apenas essa classe de elementos cruciais. (Friedman, 1981, pp. 174).

Essa visão pode ser considerada como anti-realista de hipóteses à medida que sejam consideras como realistas as hipóteses que abarcam todas as variáveis relevantes. Para ele, todas as boas teorias econômicas idealizam e simplificam em maior escala.

Friedman então afirma que "para que seja importante, uma hipótese deve ser descritivamente falsa em seus pressupostos". Esta declaração, aparentemente extravagante, gerou inúmeras controvérsias e críticas entre os economistas da época.

Entretanto, considerando que as teorias econômicas são sobretudo utilizadas pelos agentes econômicos, que buscam racionalmente maximizar o retorno esperado de seus investimentos, é um aspecto essencial que uma teoria demonstre rejeitar aspectos impossíveis de serem assumidos 
conscientemente, “(...) como supor que jogadores de bilhar calculem o ângulo e o impulso das bolas de bilhar sempre que as coloquem na caçapa" (Blaug, 1993, p. 142).

Uma teoria ou os seus 'pressupostos' não podem ser cabalmente 'realistas', no sentido descritivo imediato, que tão freqüentemente se atribui ao termo. Uma teoria completamente 'realista' do mercado do trigo teria de incluir não apenas as condições diretamente subjacentes à oferta e à demanda de trigo, como, ainda, indicações relativas à moeda ou aos instrumentos de crédito usados nos pagamentos; teria de incluir dados a respeito dos comerciantes de trigo, cor dos olhos e dos cabelos de cada comerciante, os seus antepassados, a sua educação, as pessoas da família, seus respectivos antecedentes e sua educação, e assim por diante; teria de incluir informes a respeito do tipo de solo em que o cereal foi cultivado, de suas características físicas e químicas, do estado geral do tempo na época de desenvolvimento das plantas, dos traços típicos do pessoal encarregado de cuidar da fazenda e do consumidor que, afinal, utilizará os grãos; e assim por diante; indefinidamente. (Friedman, 1981, pp. 189-90).

A função da ciência instrumental é produzir modelos que não tenham a pretensão de descrever o mundo, mas de isolar aquilo que é relevante para a resolução de problemas. Os modelos econômicos devem ser avaliados somente com base na sua capacidade preditiva, única maneira, conforme Friedman, de avaliar a cientificidade e adequação dos modelos econômicos. 


\section{Considerações filosóficas acerca do Modelo Black-}

\section{Scholes}

\subsection{A estrutura lógica}

Consideraremos o modelo Black-Scholes como uma teoria científica, e tentaremos entendê-lo a partir da concepção de ciência da Visão Recebida, esboçada na seção 2.1 .

A abordagem empirista parte da observação, e procura entender como os significados dos conceitos teóricos se baseiam nos conceitos empíricos (ou de observação).

O objeto da teoria moderna das finanças é o mercado financeiro, que envolve transações de bens e recursos que são medidos em termos de valores monetários.

Partindo dessa caracterização do objeto das finanças, o que é que se observa no mercado financeiro? Preços de ações e preços de opções (os conceitos observacionais) que são confrontados diretamente com os preços reais das opções, praticados no mercado.

A Visão Recebida não é uma abordagem empirista ingênua, como o positivismo do século XIX, mas incorpora os resultados da lógica do século XX, especialmente a noção de axiomatização desenvolvida na matemática por Hildert. Assim, o modelo de Black-Scholes é um cálculo matemático que visa a obtenção de valores de preços de opções, mas o cálculo em si pode ser estruturado de maneira formal, a partir de um certo número de axiomas ou hipóteses. 
Como hipóteses fundamentais do Modelo Black-Scholes pode-se agrupar:

H1) A taxa de juros é constante ao longo do tempo;

H2) O preço do ativo-objeto segue um caminho aleatório ao longo do tempo;

H3) O preço do ativo-objeto segue um caminho contínuo ao longo do tempo;

H4) A distribuição de preços do ativo-objeto é log-normal;

H5) A volatilidade do ativo-objeto é constante ao longo do tempo;

H6) Não há custos de transação;

H7) É possível ficar livremente comprado ou vendido em qualquer quantidade fracionária de opção ou ação;

H8) Não é possível realizar arbitragem e

H9) O mercado é perfeito.

Segundo Jarrow (cf. 1999, p. 237), as duas últimas hipóteses são determinantes na avaliação empírica do Modelo Black-Scholes.

O princípio da não arbitragem estabelece que não é possível obter lucro sem risco a partir dos preços de mercado e o do mercado perfeito afirma que é possível construir sinteticamente - através da montagem de um conjunto de operações - qualquer posição equivalente à dada por um único derivativo qualquer.

A partir dessas hipóteses, Black e Scholes incorporam a teoria utilizada na área de Transferência de Calor para derivar a Eq. (12) (p. 21). A importação 
de uma teoria matemática de uma área para outra é uma característica importante da ciência moderna, e a importação ocorrida como o modelo BlackScholes é um interessante estudo de caso.

Uma das preocupações da abordagem semântica de teorias científicas (seção 2.3) é dar conta dessa importação de maneira natural, sem ter que incluir toda uma teoria matemática (ou de outra área) dentro dos postulados da teoria sendo estudada (como tende a ser feito na abordagem sintética).

Dentre os conceitos teóricos usados na teoria das finanças, e em especial no modelo Black-Scholes, destaca-se o conceito de volatilidade, a ser discutida na seção 3.4 .

\subsection{A verificação empírica}

Com muita propriedade narra Bernstein (1997, pp. 316-7):

O artigo [de Black-Scholes] veio enfim a lume na edição de maio-junho de 1973 do Journal of Political Economy, mas somente depois da intercessão de dois membros influentes da Universidade de Chicago. $O$ artigo se revelou um dos mais influentes trabalhos de pesquisa já publicados no campo da economia ou das finanças.

Em uma dessas estranhas coincidências em que os eventos parecem vir em grupo, a Chicago Board Options Exchange iniciou suas atividades em abril de 1973, apenas um mês antes da publicação do artigo de Black-Scholes. Essa bolsa de opções, mais conhecida pelas iniciais CBOE, iniciou suas operações no salão de fumar do Chicago Board of Trade, o centro tradicional de negociação de commodities. A CBOE também prometeu uma regulamentação rigorosa das práticas de negociação, bem como a rápida informação pública de todas as transações.

No primeiro dia de negociações, 911 opções de dezesseis emissões individuais de ações mudaram de mãos. Em 1978, o volume diário subira para uma média de 100 mil contratos. Em meados de 1995, um milhão de opções de ações mudavam de mãos diariamente. Outras 300 mil opções eram negociadas em quatro outras Bolsas norte-americanas. Como cada unidade negociada de 
opção representa cem quantidades de ações, a atividade desses mercados de opções é significativa em relação ao volume das próprias Bolsas de Valores.

O CBOE agora ostenta um dos centros de negociação tecnologicamente mais sofisticados do mundo. Ele consiste em um espaçoso saguão principal, um porão com seis mil metros quadrados de computadores, fiação suficiente para circundar duas vezes o Equador e um sistema telefônico capaz de atender a uma cidade de 50 mil habitantes.

Houve uma segunda coincidência. Na mesma época em que o artigo de Black-Scholes apareceu no Journal of Political Economy e em que a CBOE iniciou suas operações, surgiu em cena a calculadora eletrônica portátil. Seis meses após a publicação do modelo de Black-Scholes, a Texas Instruments publicou um anúncio de meia página no Wall Street Journal proclamando: ‘Agora você pode encontrar o valor de Black-Scholes usando nossa... calculadora.' Em pouco tempo, os negociantes de opções empregavam termos técnicos diretamente saídos do artigo de Black-Scholes, como coeficientes de hedge, deltas e equações diferenciais estocásticas. O mundo da administração do risco ascendera a uma nova era.

No Brasil, em 2005, o mercado sobre opções da Bovespa movimentou $\mathrm{R} \$ 19,1$ bilhões $^{8}$.

Devido à sua extrema importância econômica, a fórmula apresentada por Black \& Scholes foi submetida a uma grande quantidade de testes empíricos desde sua publicação.

O que estes testes indicam, entretanto, não é exatamente a eficácia do modelo, mas a validade de suas hipóteses fundamentais (cf. Copeland \& Weston, 1988).

Os dois primeiros importantes testes do modelo foram feitos por Black \& Scholes (1972) e Galai (1977). Eles testaram a possibilidade de se obter retornos acima da taxa de juros livre de risco através da estratégia de comprar opções subavaliadas e vender opções superavaliadas. Black \& Scholes

\footnotetext{
${ }^{8}$ Relatório Anual Bovespa 2005.
} 
utilizaram dados do mercado de balcão organizado, enquanto que Galai usou dados da Chicago Board Options Exchange. Os estudos indicaram que é possível obter tais lucros sem, no entanto, garantir que eles ocorreriam sempre.

Posteriormente, Garman (1976) testou estratégias para ter ganho sem risco - "arbitragem" - com opções, através de um procedimento de cálculo que possibilita encontrar possibilidades de arbitragem em qualquer situação de mercado. O sucesso observado nos testes indicou que o Modelo Black-Scholes é eficiente em apontar situações de ganho sem risco.

No Brasil, vale destacar o estudo feito por Becker \& Lemgruber (1989), que utilizou diversas estratégias de gestão de carteiras contendo opções e ações e dados da Bolsa de Valores de São Paulo. O lucro foi observado para algumas das estratégias adotadas.

Cabe ressaltar que em todos estes estudos, se forem considerados os custos de transação, o lucro tende a desaparecer ou ser insignificante.

\subsection{Os aprimoramentos}

Algumas das hipóteses do Modelo Black-Scholes foram testadas empiricamente e deram ensejo a novas idéias, que serão consideradas aqui como "aprimoramentos".

No esquema abaixo (Fig. 2), os aprimoramentos que seguiram ao Modelo Black-Scholes estão relacionados às hipóteses fundamentais que foram objeto de análise, e serão sumariamente descritas a seguir. 




Figura 2: Aprimoramentos relacionados ao Modelo Black-Scholes.

(a) O modelo Black-Scholes assume que a distribuição de probabilidade do preço do ativo-objeto é lognormal $(\mathrm{H} 4)$. Esta talvez seja a premissa mais criticada do modelo (cf. Costa, 1998, p. 60). Para superar esta limitação, um ajustamento proposto consiste em utilizar distribuições observadas diretamente do comportamento dos preços de mercado. Com isso, pretende-se evitar o fenômeno da "curtose" - medida que indica a concentração de observações nas caudas da distribuição. Se a cauda da distribuição real for diferente da estimada pela distribuição lognormal, haverá uma discrepância direta nos dados usados na fórmula de Black-Scholes.

(b) Outro motivador de ajustes ao modelo trata da hipótese de constância da taxa de juros ao longo do tempo $(\mathrm{H} 1)$, especialmente em 
aplicações no mercado brasileiro. Teoricamente, uma correção para esta hipótese consiste em acrescentar uma variável de volatilidade relativa à taxas de juros, o que torna os cálculos extremamente complicados. Na prática, há a possibilidade de se utilizar dados numéricos estimados para a variável taxa de juros em função do prazo até o exercício. Merton (1973) produziu resultados a partir da modelagem estocástica de taxa de juros.

Cabe também mencionar os fenômenos de autocorrelação - que implica em dependência, em alguma medida, da volatilidade aos valores anteriores e de heterodasticidade que, no caso do preço do ativo-objeto, implica que os valores dos retornos dos preços das ações possuem o efeito de "reversão à média", que seria uma tendência em convergir para algum valor histórico.

Costa (1998, pp. 64-5) demonstra através de um experimento simples que H2 e H4 não são observadas no mercado. Com valores da ação Vale PN, no período de 1990 a 1994, calculou-se o valor de volatilidade diária $(\sigma d)$ dos retornos para períodos de $n$ dias. Se $\mathrm{H} 4$ se observa, tem-se que:

$$
n=\frac{\left(\sigma_{n}\right)^{2}}{\left(\sigma_{d}\right)^{2}}
$$

na qual on é a volatilidade para o período $n$ considerado. Os resultados encontram-se na tabela abaixo: 


\begin{tabular}{|c|c|c|}
\hline $\mathbf{n}$ & $(\boldsymbol{\sigma n})^{\wedge} \mathbf{2} /(\boldsymbol{\sigma d})^{\wedge} \mathbf{2}$ & $\boldsymbol{\sigma d}$ \\
\hline 1 & 1,00 & 87,93 \\
\hline 5 & 4,53 & 83,71 \\
\hline 10 & 9,40 & 85,26 \\
\hline 20 & 18,82 & 85,31 \\
\hline 40 & 32,67 & 79,47 \\
\hline 80 & 59,58 & 75,89 \\
\hline 120 & 79,09 & 71,39 \\
\hline
\end{tabular}

Figura 3: Tabela contendo valores de desvio padrão de retornos para a ação VALE PN no período de 1990 a 1994.

A diferença constatada no tratamento dos dados pela fórmula (15) com o período considerado para a medição constata que os valores dos retornos tendem a um valor médio ao longo do tempo, e que os preços podem não seguir um caminho perfeitamente aleatório.

(c) A hipótese de continuidade do preços dos ativos-objeto (H3), necessária para a adoção do cálculo estocástico, também foi alvo de relaxamento. Cox, Ross \& Rubinstein (1979) modelaram a ação considerando saltos nos preços e Merton (1976) sugeriu um modelo com saltos sobrepostos ao movimento browniano geométrico.

Diversos outros autores trabalharam o relaxamento das hipóteses do modelo Black-Scholes. Uma síntese comparativa dos primeiros estudos pode ser consultada em Smith (1976).

\subsection{A volatilidade}

Outros importantes aperfeiçoamentos ao modelo tratam de volatilidade, que serão abordados a seguir. 
Conforme Sandroni (2005, p. 886), a volatilidade é a

medida da intensidade e freqüência das flutuações dos preços de um ativo financeiro ou dos índices numa Bolsa de Valores. É o desvio padrão das mudanças do logaritmo dos preços de um ativo (financeiro), expressos numa taxa anual. A volatilidade é uma variável que aparece nas fórmulas de opções. As unidades desta variável são tais que o quadrado da volatilidade multiplicado pela term-to-maturity é um número puro (unity-free ). Aplicado aos derivativos, evidencia o grau de dispersão das variações ocorridas no preço (aumento ou redução) de um ativo.

A volatilidade constitui o único parâmetro do modelo que não é diretamente observável no mercado (cf. Hull, 1998, p. 557).

(d) Macbeth e Merville (1979) substituíram na fórmula de Black-Scholes os preços das opções pelos preços observados no mercado, obtendo como resultado a volatilidade. Essa metodologia fornece o que é conhecido por "volatilidade implícita". O que o estudo constatou foi que a volatilidade implícita é maior nas opções cujo strike está muito acima (fora-do-dinheiro) ou muito abaixo (dentro-do-dinheiro) do preço atual da ação. Esse fenômeno ficou conhecido no mercado como "sorriso da volatilidade" e significou uma importante refutação empírica ao modelo Black-Scholes (refutação a H5).

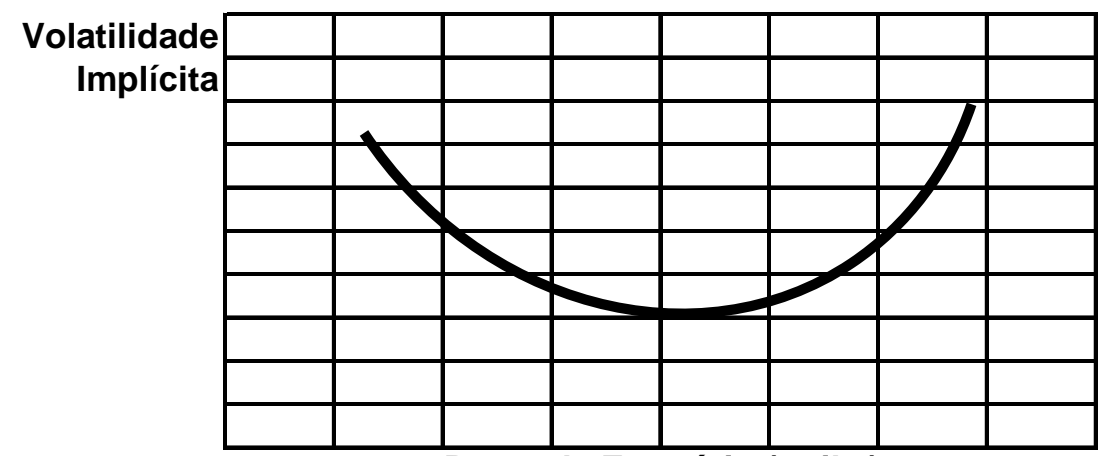

Preço de Exercício (strike)

Figura 4: Gráfico esquemático representando o fenômeno do "sorriso da volatilidade" 
(e) Uma das formas de lidar com essa imperfeição é a utilização de uma "matriz de volatilidades implícitas" na qual se colocam os valores das volatilidades implícitas para cada série de opção, sendo que as mais "confiáveis" são as mais negociadas. A partir desses dados recorre-se a técnicas de cálculo numérico visando prever o melhor valor possível para a volatilidade que será efetivamente usada como parâmetro do modelo.

(f) Se for considerado que a volatilidade varia com o tempo - possui estrutura a termo - pode-se associar a ela o tratamento estocástico, nos moldes do estudo que Merton (1973) realizou com taxas de juros estocásticas.

Conforme Mendes \& Duarte (1999), a volatilidade é hoje um dos conceitos mais importantes em Finanças.

Em 2003, Robert F. Engle recebeu o Prêmio Nobel em Economia pelos estudos em cálculo de volatilidades que resultaram no modelo GARCH (Engle, 1982). 


\section{Conclusão}

O Modelo Black-Scholes propõe uma fórmula para calcular o valor do preço de opções do tipo européia a partir de informações de mercado e de um parâmetro que não é diretamente observável: a volatilidade.

A função do modelo, porém, não é determinar o que a fórmula permite calcular: o prêmio das opções. Foi visto que a incapacidade preditiva do modelo, devido às hipóteses subjacentes aos mercados e ao comportamento de ações e opções, é esperada e normalmente constatada nos estudos e aplicações. Essa característica, portanto, não abalou o sucesso e a imensa aceitação que o modelo teve no âmbito das Finanças.

Vale notar que é crucial a delimitação da realidade do Black-Scholes. Para isso, seria indispensável uma análise mais aprofundada do fenômeno denominado "mercado", que fica como sugestão para trabalhos posteriores. Se o mercado é a realidade de que trata o modelo, a análise aqui fornecida expõe uma visão instrumentalista dessa ferramenta.

A incapacidade preditiva não é restrita apenas ao Black-Scholes, mas está presente em outros modelos econômicos. Para o modelo em questão resta refletir quais teriam sido os critérios de aceitabilidade que proporcionaram seu sucesso e o prêmio Nobel de economia em 1997.

Os avanços proporcionados pelas limitações impostas pelas hipóteses adotadas pelo modelo fomentou a "indústria acadêmica de pesquisa em derivativos" e pode ser considerado o maior trunfo de Black-Scholes. 
Um mercado somente pode se expandir se o conhecimento dos agentes a seu respeito aumentar. Os modelos de apreçamento têm como função primordial tornar mais transparente o processo de formação de preços em função de outros parâmetros também disponíveis no mercado. Nas palavras de Hull (1998, pp. 560-1), "na prática, um modelo de apreçamento de opções não passa de uma ferramenta para compreender o ambiente de volatilidade e apreçar ativos sem negociação de modo consistente com os preços de mercado de títulos ativamente negociados".

No plano teórico, entretanto, as bases lançadas pelo Modelo BlackScholes possibilitaram a expansão dos instrumentos financeiros de forma rápida e segura, conforme já foi apresentado. A escolha metodológica por Friedman não foi apropriada, uma vez que o presente trabalho se propôs a examinar um ferramenta econômica prática diretamente sob a óptica da Filosofia da Ciência, sem recorrer aos instrumentos da metodologia da Economia. Devido ao caráter controverso de seu trabalho, Friedman não prescinde de uma análise mais ampla e contextual, o que não foi realizado nessa dissertação.

O que ocorre no plano empírico é que o Modelo Black-Scholes cria a sua própria realidade através da crença dos agentes ou pela normatização que o próprio modelo fez surgir. Os agentes preferem acreditar no modelo para que nenhum deles "erre sozinho" ao deixar de utilizá-lo. E a normatização se dá pela forma amplamente divulgada que o modelo passou a ser usado, em grande parte atribuída aos avanços tecnológicos da época (calculadora, bolsa de Chigaco). 
O aspecto da determinação da volatilidade pode ser compreendida como uma "proteção" do modelo às inadequações empíricas que possam ensejar questionamentos teóricos. Ela guarda uma grande gama de imperfeições advindas do desajustamento do modelo à realidade apresentada, por exemplo, nas hipóteses assumidas em sua formulação. $\mathrm{Na}$ impossibilidade ou na dificuldade teórica de se relaxar estas hipóteses, procura-se adequar a determinação da volatilidade através de experiências numéricas e empíricas, como a adoção de uma "matriz de volatilidade" ou modelando a própria volatilidade de forma estocástica.

Preços de mercado são definidos pela livre negociação. Um primeiro passo para que um modelo de apreçamento não tenha aceitabilidade seria a característica de determinação objetiva e inflexível de preços "corretos" de negociação. Daí decorre o que se poderia denominar "contradição dos modelos de apreçamento": ter grande aceitabilidade apesar de não se constatarem objetivamente em testes empíricos. E essa contradição existiria para evitar outra: a de se ter livre negociação de preços a despeito de existirem preços corretos e determinados para eles devido a algum modelo de grande aceitação. 


\section{Referências Bibliográficas}

Becker, J. L. \& Lemgruber, E. F. (1989) - "Uma análise de estratégias de negociação no mercado brasileiro de opções: evidências a partir das opções de compra mais negociadas durante o plano cruzado", in Brito, N. R. O (org) - Gestão de Investimentos, Atlas, São Paulo: cap. 13.

Bernstein, P. L. (1997) - Desafio aos deuses, Campus, Rio de Janeiro, $10^{\mathrm{a}}$ ed.

Black, F. \& Scholes, M. (1972) - "The valuation of option contracts and a test of market efficiency", Journal of Political Economy, Chicago, v.27: 497-505.

- (1973) - "The pricing of options and corporate liabilities", Journal of Political Economy, Chicago, v. 81: 637-59.

Blaug, M. (1993) - Metodologia da Economia, Edusp, São Paulo.

Bodie, Z. \& Merton, R. C. (2002) - Finanças, Bookman, Porto Alegre.

Boyd, R. (1973) - "Realism, underdetermination and a causal theory of evidence", Nous 7: 1-12.

Copeland, T. E. \& Weston, J. F. (1988) - Financial theory and corporate policy, Addison-Wesley, Boston, $3^{\mathrm{a}}$ ed.

Costa, C. L. (1998) - Opções: operando a volatilidade, Bolsa de Mercadorias \& Futuros, São Paulo. 
Cox, J. C. \& Ross, S. A. \& Rubinstein, M. (1979) - "Option pricing: a simplified approach", Journal of Financial Economics 7, Rochester: 229-63.

Engle, R. F. (1982) - "Autoregressive conditional heteroscedasticity with estimates of the variance of United Kingdom Inflation", Econometrica 50: 987-1007.

Feigl, H. ([1970] 2004) - "A visão 'ortodoxa' de teorias: comentários para defesa assim como para crítica", Scientiae Studia, São Paulo, v.2, n. 2: $265-77$.

Friedman, M. (1953) - "The metodology of positive economics" in Essays in positive economics, Chicago University Press, pp. 3-43.

— (1981) - A metodologia da economia positive, Multiplic, v.1 , n.3, São Paulo, pp. 163-200.

Galai, D. (1977) - "Test of market efficiency and the Chicago Board Options Exchange", Journal of Business 50, Chicago: 167-97.

Garman, M. B. (1976) - "An algebra for evaluating hedge portfolios", Journal of Financial Economics 3, Rochester: 403-27.

Giere, R. N. (1999) - Science without laws, Chicago Press, Chicago. Heilbroner, R. (1996) - A história do pensamento econômico, Nova Cultural, São Paulo.

Horwich, P. (1990) - Truth, Basil Blackwell.

Hull, J. (1998) - Opções, futuros e outros derivativos, BM\&F, São Paulo, $3^{\mathrm{a}} \mathrm{ed}$ 
Itô, K. (1951) - "On stochastic differential equations", Memoirs, American Mathematical Society 4, Providence: 1-51.

Jarrow, R. A. (1999) - "In honor of the Nobel laureates Robert C. Merton and Myron S. Scholes: a partial differential equation that changed the world", Journal of Economic Perspectives, Pittsburgh, v. 13, n.4: 229-48.

Jevons, W. S. ([1871] 1983) - A teoria da economia política, Abril Cultural, São Paulo.

Laudan, L. et al. (1986) - "Scientific change: philosophical models and historical research", Synthese 69: 141-223. (Tradução brasileira publicada pela revista Estudos Avançados-USP 19 (1993): 7-89.

Macbeth, J. D. \& Merville, L. J. (1979) - "An empirical examination of the Black-Scholes call option pricing model", Journal of Finance, Berkeley v. 34, n. 5: 1173-86.

Markowitz, H. M. (1952) - "Portfolio selection", Journal of Finance, Berkeley, v. 7.

- (1959) Portfolio selection: efficient diversification of investment, John Wiley and Sons.

Mendes, B. V. M. \& Duarte Jr., A. M. (1999) - Modelos estatísticos aplicados ao mercado financeiro brasileiro, SINAPE.

Merton, R. C. (1973) - "Theory of rational option pricing", Bell Journal of Economics and Management Science 4: 141-83. 
— (1976) - "Option princing when underlying stock returns are discontinuous", Journal of Financial Economics 3, Rochester: 12546.

— (1997) - "Applications of option-pricing theory: twenty-five years later", Nobel lecture: 85-118.

Miller, M. \& Modigliani, F. (1958) - "The cost of capital, corporation finance and the theory of investment", American Economic Review, Pittsburgh.

— (1963) - "Taxes and the cost of capital: a correction", American Economic Review, Pittsburgh.

- (1966) - "Some estimates of the cost of capital in the electric utility industry", American Economic Review, Pittsburgh.

Pessoa Jr., O. (2004) - "O canto do cisne da visão ortodoxa da Filosofia da Ciência", Scientiae Studiae, São Paulo, v. 2, n. 2: 259-63.

Plastino, C. E. (1995) - Realismo e anti-realismo acerca da ciência: considerações filosóficas sobre o valor cognitivo da ciência, Tese de Doutorado na FFLCH-USP.

Robbins, L. (1935) - An Essay on the Nature and Significance of Economic Science, MacMillan, Londres, $2^{\mathrm{a}}$ ed.

Sandroni, P. (2005) - Dicionário de economia do século XXI, Record, Rio de Janeiro.

Say, J. B. ([1803] 1983) - Tratado de economia política, Abril Cultural, São Paulo. 
Sharpe, W. F. (1964) - "Capital asset prices: a theory of market equilibrium under conditions of risk", Journal of Finance, Berkeley, v. $19: 425-42$

Silva, M. R. (1998) - "Realismo e anti-realismo na ciência: aspectos introdutórios de uma discussão sobre a natureza das teorias", Revista Ciência \& Educação, 5(1).

Smith, C. (1976) - "Option pricing: a review", Journal of Financial Economics 9, Rochester: 3-54.

Suppe, F. (1977) - "The search for philosophic understanding of scientific theories", The structure of scientific theories, University of Illinois, $2^{\mathrm{a}}$ ed: $1-241$

- (1989) - The semantic conception of theories and scientific realism, University of Illinois.

van Fraassen, B. (1980) - "Arguments concerning scientific realism", The scientific image, Clarendon Press: 6-40. 